\title{
Paradoxical Skin Reaction to Certolizumab, an Overlap of Pyoderma Gangrenosum and Psoriasis in a Young Woman Treated for Ankylosing Spondylitis: Case Report with Literature Review
}

\author{
Anna Gawdzik • Małgorzata Ponikowska • Alina Jankowska-Konsur • \\ Zdzisław Woźniak · Joanna Maj · Jacek C. Szepietowski iD
}

Received: April 16, 2020 / Published online: May 23, 2020

(C) The Author(s) 2020

\begin{abstract}
Introduction: Biologic agents form an indispensable part of modern therapeutic regimens for the treatment of severe inflammatory diseases, especially in the fields of rheumatology, dermatology and gastroenterology. They are favoured by both physicians and patients due to their high effectiveness, good patient tolerance and safety. However, interference in the regulation and dynamics of inflammatory cytokines can on occasion lead to an onset of a dermatological condition also known as paradoxical skin reaction. Here, we present a case of paradoxical skin reaction induced by certolizumab. Case Report: A young woman with ankylosing spondylitis developed a severe and complex cutaneous reaction after 6 months of otherwise successful treatment with certolizumab. The
\end{abstract}

Digital Features To view digital features for this article go to https://doi.org/10.6084/m9.figshare.12301748.

A. Gawdzik · M. Ponikowska · A. Jankowska-Konsur .

J. Maj · J. C. Szepietowski ( $₫)$

Department of Dermatology, Venereology and

Allergology, Wroclaw Medical University, Wrocław,

Poland

e-mail: jacek.szepietowski@umed.wroc.pl

Z. Woźniak

Department of Pathomorphology, Wroclaw Medical

University, Wrocław, Poland diagnosis of a rare paradoxical cutaneous reaction post anti-tumour necrosis factor alpha treatment was based on overlapping features of pyoderma gangrenosum and palmoplantar pustular psoriasis. Alopecia developed and there was also nail involvement. Treatment proved to be challenging as the disease did not remit after the patient ceased treatment with certolizumab. The patient was started on a combination of secukinumab and methotrexate to control the symptoms, with a promising outcome.

Conclusion: Paradoxical skin reactions are an emerging clinical entity that require further research in order to establish risk factors and best personalized treatment.

Keywords: Anti-TNFa drugs; Certolizumab; Palmoplantar pustular psoriasis; Paradoxical reaction; Pyoderma gangrenosum 


\section{Key Summary Points}

A rare case of a certolizumab-induced dermatosis with clinical features of overlapping pustular psoriasis and pyoderma gangrenosum with alopecia and nail involvement is described.

A review of the literature on paradoxical skin reactions to anti-tumour necrosis factor alpha drugs was performed, with a special focus on the reactions provoked by certolizumab.

The clinical strategy involved cessation of treatment with certolizumab and a switch to a new biologic treatment with secukinumab combined with methotrexate.

Further research on the pathomechanisms and optimal treatment of paradoxical skin reactions is required.

\section{INTRODUCTION}

A new class of side effects known as paradoxical reactions is an emerging threat arising from the increasing use of anti-tumor necrosis factor alpha $(\mathrm{TNF} \alpha)$ drugs in treatment regimens. TNf $\alpha$ drugs are now highly accessible and known to be highly effective. Immune-mediated inflammatory diseases are complex clinical entities that can be both improved and induced by interference in the dynamics of the inflammatory cytokine response. We present a rare variant of a paradoxical skin reaction induced by the anti-TNF $\alpha$ drug certolizumab that manifested in multiple locations with overlapping features of pyoderma gangrenosum and psoriasis.

This case report was written after receiving oral and written consent from the patient and is compliant with the University Hospital ethical guidelines. Written consent was also obtained from the patient for the publication of clinical photographs.

\section{CASE REPORT}

A 34-year old Caucasian woman treated for ankylosing spondylitis (AS) with certolizumab for 6 months was admitted to our department with symptoms of palmoplantar pustulosis of 2 months duration accompanied by painful abscesses on the arc of the feet, painless abcesses on the breast and pubic mount and hair loss and severe desquamation in the frontoparietal area.

The patient was diagnosed with AS in 2006 with positive HLB27 antigen and a family history of AS. Due to its progressive course complicated by recurrent uveitis, the patient was being treated with certolizumab $200 \mathrm{mg}$ injected subcutaneously (s.c.) every 2 weeks, with good clinical response. No side effects had been reported until the onset of skin lesions. During month 6 of treatment with certolizumab, pustules on an erythematous base with desquamation developed symmetrically on the patient's palms and feet. Enhanced sweating of the palms and soles was noted. A layer of thick yellowish scale on the scalp appeared simultaneously. Initially the patient was suspected of acquiring a Coxsackievirus infection. No improvement was noted with either topical treatment with hydrocortisone, natamycin and neomycin cream and salicylic oil or following treatment with more potent steroids, including clobetasol propionate. The lesions kept exacerbating despite discontinuation of the anti-TNF $\alpha$ treatment. Extensive scaling of the scalp with hair loss, painful abscesses on the lower surface of the right breast and pubic area, abscesses on a violaceous base that excreted pus and blood and several tiny pustules on the back and left calf were noted. There was no personal or family history of psoriasis or other skin diseases. The patient has been an active smoker for 15 years and denied abuse of other substances.

One week prior to admission the patient had received an empiric treatment with oral clarithromycin $500 \mathrm{mg}$ twice daily due to an upper respiratory tract infection. Following treatment 


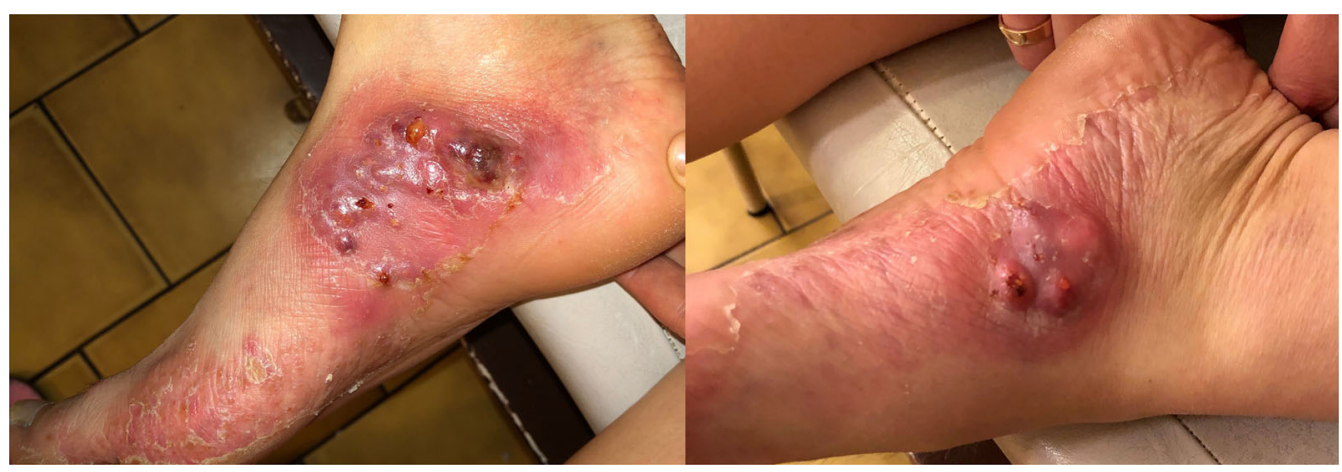

Fig. 1 Plantar lesions on the foot of the patient on admission

initiation, the respiratory symptoms subsided but the skin lesions persisted, causing a significant decline in the patient's quality of life due to severe pain and disability. Smaller pustules on a violaceous basis appeared a few days prior to the admission, on the left calf.

On admission the patient presented symptoms of pustular psoriasis of the palms and soles accompanied by abscesses on a violaceous basis with a clinical resemblance to pyoderma gangrenosum (Fig. 1). Two smaller abscesses were found on the right breast, in the pubic area and on the left calf. Plaque with silver scale developed on the occipital area of the scalp, with an alopecia, that was positive for the pull test.

Swabs for bacteriological and mycological cultures were performed, and both were negative. The only deviations in the laboratory test results were slightly elevated inflammatory markers, including C-reactive protein $(10.9 \mathrm{mg} /$ l) and erythrocyte sedimentation rate $(50 \mathrm{~mm} /$ h), minor leucocytosis $\left(10.62 \times 10^{3} / \mathrm{ul}\right)$ and neutrophilia $\left(6.88 \times \times 10^{3} / \mathrm{ul}\right)$. Chest X-ray showed no obvious pathology.

Treatment was initiated with a once-daily dose of hydrocortisone $200 \mathrm{mg}$ administered intravenously. Additional therapy was implemented with an oral antibiotic treatment comprising doxycycline $200 \mathrm{mg}$ daily combined with nonsteroidal non-inflammatory drugs (ketoprofen) and a topical treatment with a boric acid solution and betamethasone with gentamycin cream. However, there was only a mild improvement in the condition and only a mild reduction in pain intensity. Secukinumab (anti-interleukin [IL] 17A) was then added as a new biologic treatment of both the AS and the reaction to certolizumab, at a dose regimen of $150 \mathrm{mg}$ at weeks $0,1,2,3$ and 4 , followed by a dose of $150 \mathrm{mg}$ every 4 weeks. After two doses of secukinumab, a new lesion developed on the patient's right thigh which subsequently developed into an abscess from which there was a constant purulent discharge that appeared on the lateral surface of the right thigh (Fig. 2); there was increased desquamation on the scalp and feet; and there was an enlargement of the plantar and breast lesions, with a purulent discharge (Fig. 3). The pain was severe (numeric rating scale 10/10), and the patient required opioid analgesics. A pathergy phenomenon was observed at the site of venipuncture (Fig. 3c). Onychomadesis and onycholysis of the fingernails became visible (Fig. 4). A surgical skin biopsy was taken from the patient's left calf for histopathologic examination. It showed an erosion filled with neutrophils, epidermis with irregular acantholysis and abundant underlying neutrophilic infiltration in the dermis, with a tendency to perivascular accumulation and leukocytoclasis. This clinical picture was interpreted by the pathologist to be indicative of pustular psoriasis (Fig. 5).

Having taken into consideration the clinical and histological picture, a diagnosis of overlapping palmoplantar pustular psoriasis, scalp psoriasis and pyoderma gangrenosum as a paradoxical skin reaction to the anti-TNF $\alpha$ drug was made.

A decision was taken to add once-weekly methotrexate (MTX) $20 \mathrm{mg}$ s.c to the treatment with secukinumab. Follow-up after 2 months of 


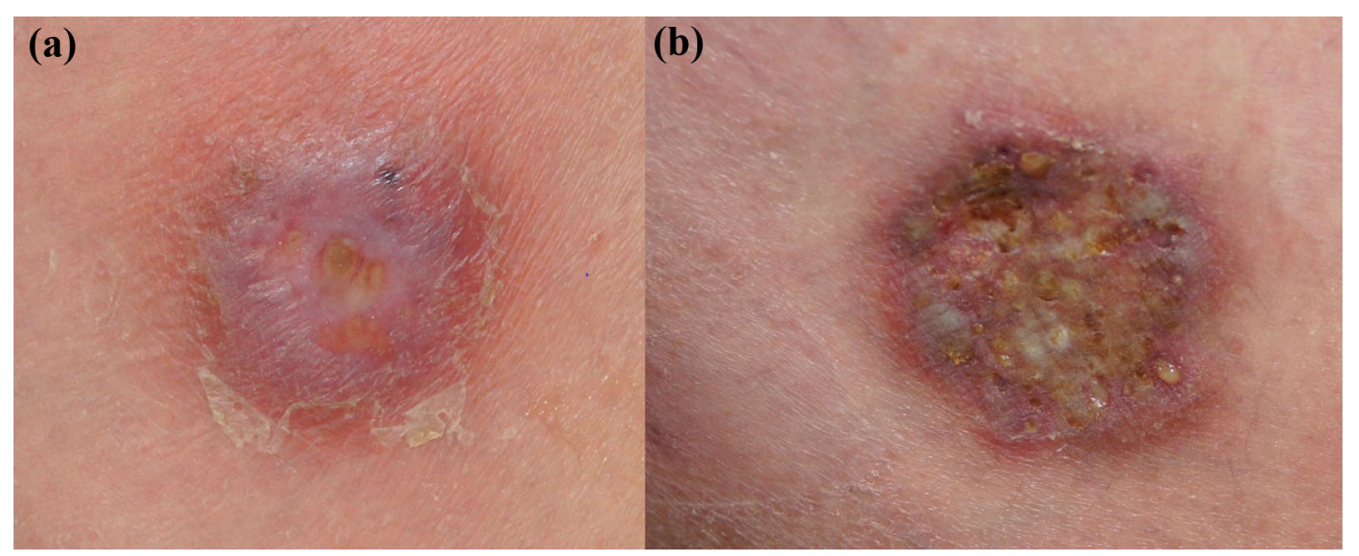

Fig. 2 Lesion on the right thigh. a Ulceration that developed from a pustule before treatment with methotrexate (MTX), b ulceration after 1 month of treatment with once-weekly MTX $20 \mathrm{mg}$ administered subcutaneously

combined therapy with secukinumab and MTX showed a regrowth of hair and less undermined lesions with less inflammatory borders, as well as ulcerations that were healing, with cribriform scars on the previously pustular lesions (Fig. 6).

\section{DISCUSSION}

The development and introduction of biologic drugs into the clinical setting was a breakthrough in the treatment of immune-mediated inflammatory diseases in the fields of rheumatology, dermatology and gastroenterology. The advantages of biologic drugs compared with classic disease-modifying drugs are well documented and include high effectiveness, good patient tolerance and relatively low risk of adverse effects [1].

$\mathrm{TNF} \alpha$ inhibitors, such as infliximab, etanercept, adalimumab, golimumab and certolizumab, are effective in treating rheumatoid arthritis, seronegative spondyloarthropaties, Crohn's disease, psoriasis and psoriatic arthritis. These biological drugs can also be useful to treat patients with refractory pyoderma gangrenosum or hidradenitis suppurativa as well as Behçet disease, Sweet's syndrome, subcorneal pustulosis (Sneddon-Wilkinson syndrome) and sarcoidosis [2].

The documented adverse effects of TNF $\alpha$ inhibitors include increased risk of severe infections (especially mycobacterial), neoplasms (lymphomas, melanoma and nonmelanoma skin cancers) and auto-immune disorders (i.e. lupus-like reactions, vasculitis, urticaria) and adverse effects referred to as paradoxical reactions $[1,3]$. The latter are usually diagnosed during the course of a biological treatment; especially during the first year of treatment, novel skin lesions can appear or there can be exacerbation or changes in the phenotype of an already existing skin condition. A new inflammatory-mediated skin disease that develops as an adverse effect is also one that usually responds well to treatment with the same biologic agent. For example, infliximab has been recognized for its efficacy in psoriasis [4], but it can also induce de novo psoriasis [3] as well as the evolution of plaque psoriasis to different morphological forms, such as palmoplantar pustular psoriasis [1, 3-5].

Paradoxical cutaneous reactions are considered by the medical community to be rather uncommon, with a prevalence that varies from 0.6 to $5.3 \%$ in the general population [1]. The risk of developing this reaction is the highest during the first year of the treatment [6]. Genetic polymorphism is considered to be one of the etiological factors [7]. On a molecular level, such reactions develop as a result of an imbalance in cytokine activities. One of the mechanisms underlying paradoxical psoriatic reactions involves increased INF $\gamma$ production by activated plasmocytoid dendritic cells as a consequence of diminished $\mathrm{TNF} \alpha$ levels because 


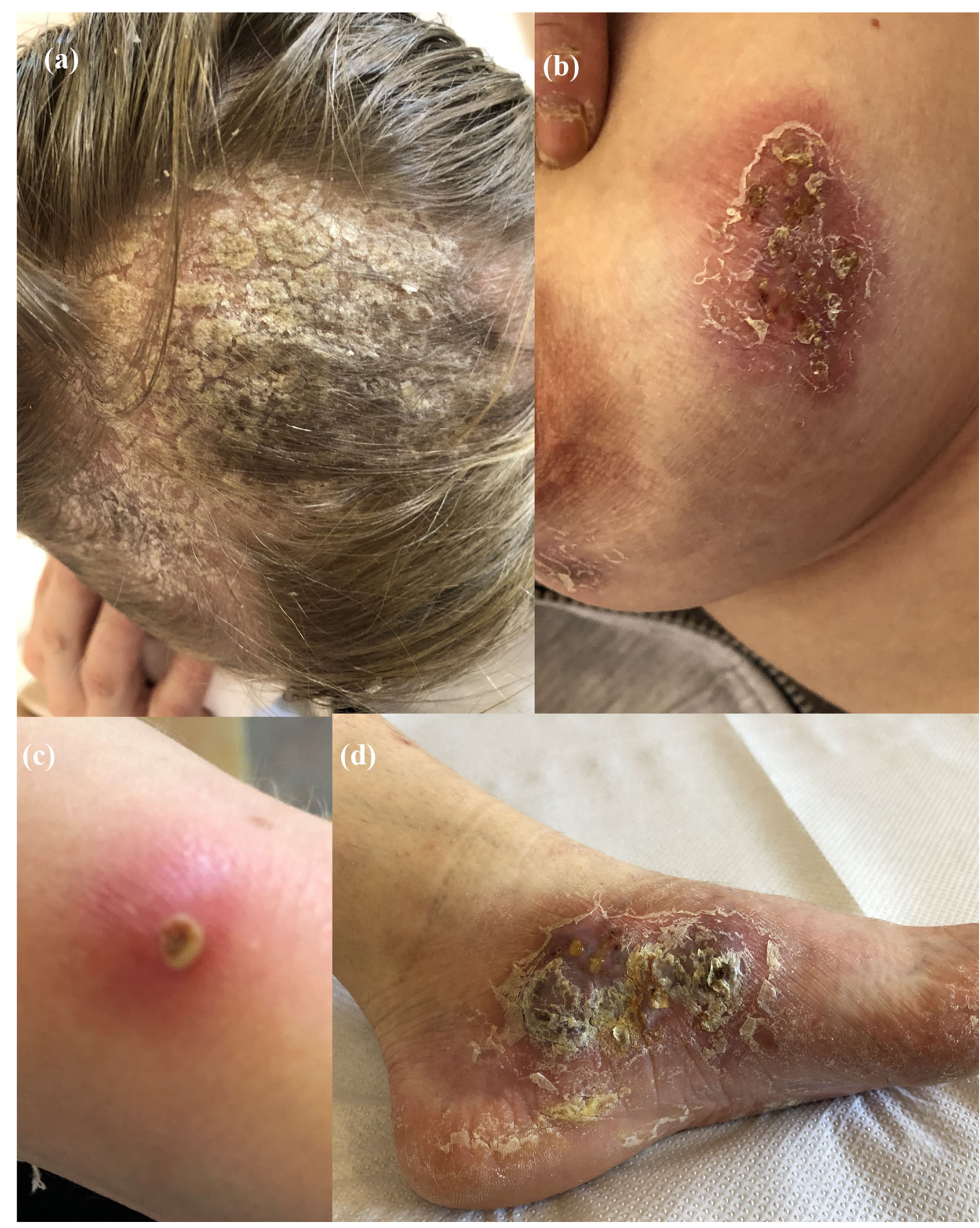

Fig. 3 a Multiple locations of the certolizumab-induced dermatosis on scalp, an exacerbation, prior to initiation of treatment with MTX, showing psoriatic scalp lesions with hair loss, $\mathbf{b}$ multiple pustules on a violaceous basis on the

TNF $\alpha$ has a suppressive effect on INF $\gamma$. Other possibilities include enhanced expression of CXCR3 chemokine, which induces the migration of auto-reactive $\mathrm{T}$ cells to the skin, and increased production of INF $\gamma, \mathrm{TNF} \alpha$ and IL-17 right breast, $\mathbf{c}$ pathergy on the left forearm at site of venipuncture, $\mathbf{d}$ abscesses and pustules on the feet with desquamation

$[1,4]$. These proposed mechanisms formed the basis of our decision to initiate our patient on a treatment regimen that included secukinumab.

A classification of paradoxical cutaneous reactions has been proposed that combines 


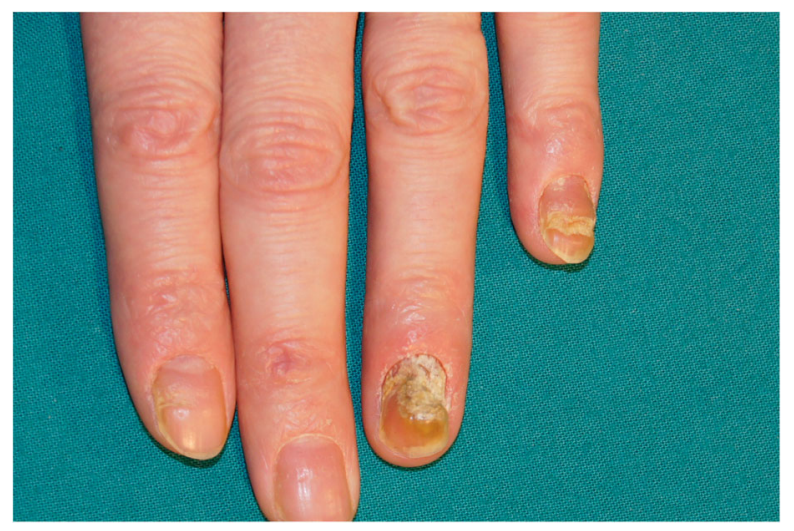

Fig. 4 Fingernail onychomadesis

both the clinical and pathologic aspects of these adverse cutaneous eruptions [1]. Most cases are of the psoriasiform type [1], with the most common variant of paradoxical psoriasis reported to be palmoplantar pustulosis [3], being diagnosed in $42.9 \%$ of cases. Less common variants are plaque (14.7\%) and guttate psoriasis $(10.9 \%)$ [8]. Scalp involvement has been observed in $7 \%$ of all cases of anti-TNF $\alpha$ druginduced psoriasis [8]. Some patients may develop psoriatic alopecia, which has been described as a new phenotype of an anti-TNF $\alpha$ cutaneous reaction with histological presentation of overlapping features of psoriasis and alopecia areata [9]. There is also a possibility of inducing a pure form of patchy or universalis alopecia areata [4]. Other, rare presentations include lichenoid-pattern reactions, eczematous, hidradenitis suppurativa-like reactions and granulomatous (sarcoidosis, granuloma annulare, necrobiosis lipoidica) or neutrophilic reactions, including pyoderma gangrenosum or Sweet's syndrome [1, 10]. A presentation can be typical or overlapping and be vague both clinically and histologically, thereby posing a diagnostic challenge [1]. There is also a possibility of inducing a paradoxical systemic reaction. Cases of Crohn's disease in patients treated for psoriasis with TNF $\alpha$ inhibitors or of a mediastinal and pulmonary sarcoidosis have been reported [4].

Pyoderma gangrenosum (PG) is a rare inflammatory neutrophilic dermatosis with a clinical presentation that in most cases follows a pattern of an evolution from a nodule or a pustule to a usually painful ulceration with undermined, violaceous borders [11]. Other variants are possible, including vegetative, bullous and pustular forms [12]. In about 30\% of cases the pathergy phenomenon is observed (as also in our case) [11], which is considered to be a pathognomonic feature as histology is not considered to be the best diagnostic tool. The most common sites are the lower extremities, but it can affect other locations as well. The lesions can be disseminated. There is a female predilection [11, 12]. The disease may begin after a focal skin traumatism, such as surgery, or in association with inflammatory bowel disease, myeloproliferative disorders or rheumatoid arthritis. On rare occasions, patients can also be diagnosed with AS [11]. Topical treatment with

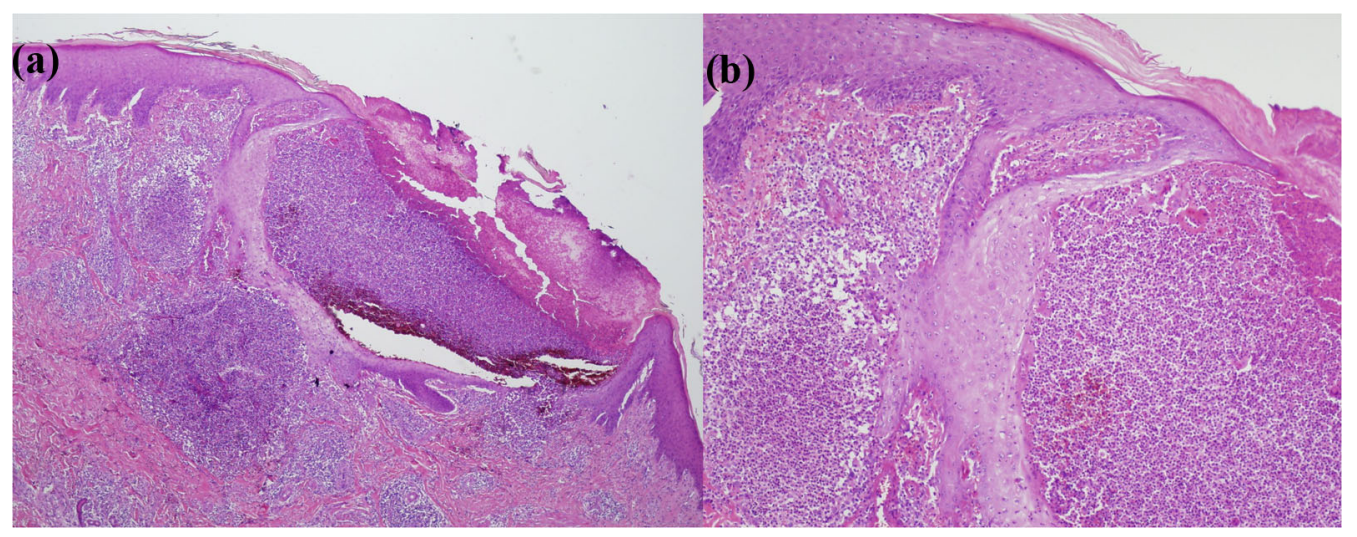

Fig. 5 Histopathology of a pustular lesion from the left lower extremity (staining: hematoxylin and eosin). a Magnification $\times 40$, b magnification $\times 100$ 


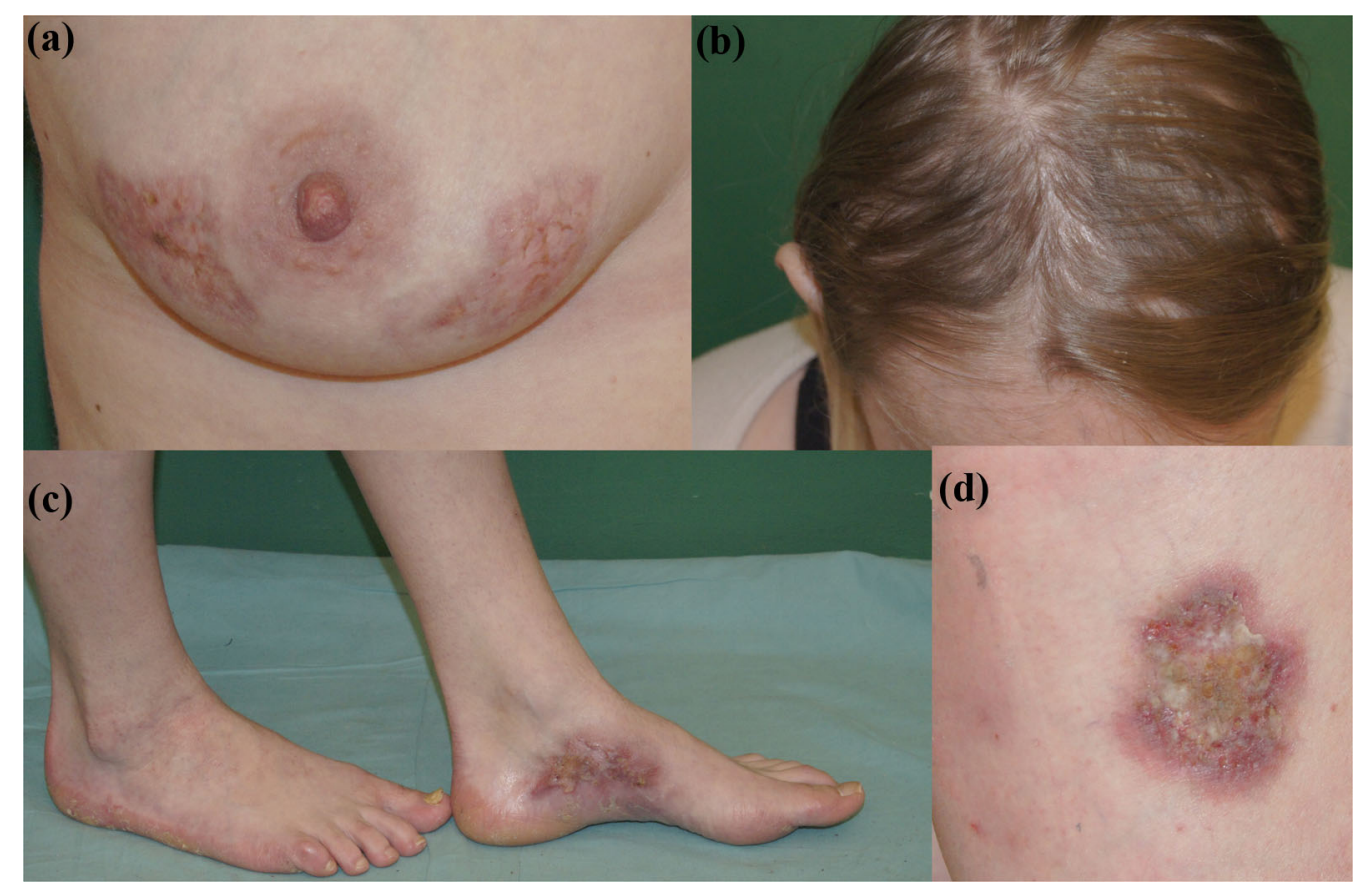

Fig. 6 Lesions after 4 months on therapy with secukinumab followed by 2 months on combined therapy of secukinumab + once-weekly MTX $20 \mathrm{mg}$ subcutaneously. a Right breast, $\mathbf{b}$ scalp, $\mathbf{c}$ feet, $\mathbf{d}$ right thigh

steroids and calcineurin inhibitors is rarely successful as a monotherapy, and systemic treatment with cyclosporine in combination with systemic steroids is frequently required. Alternative options are azathioprine, dapsone, cyclophosphamide, MTX and intravenous immunoglobulin [12]. Anti-TNF $\alpha$ drugs, mostly infliximab and adalimumab, have an established efficacy in the treatment of refractory PG $[1,12]$. However, both biologics have been associated with inducing PG as a paradoxical skin reaction $[1,13]$. One of the first reports on PG in a patient treated with anti-TNF $\alpha$ was published in 2009, in which the authors described a case of disseminated and peristomal PG after 6 months of treatment with infliximab for Crohn's disease. It was not certain whether the severity of the inflammatory bowel disease or a colostomy could have been an inducing factor regardless of anti-TNF $\alpha$ or whether all mechanisms were equally involved. The patient remained on infliximab with added prednisolone and died of sepsis 7 months later [14]. Golimumab and etanercept have also been reported as possible inductors of PG $[15,16]$.
In the PubMed database, we found only two cases of refractory disseminated PG successfully treated with certolizumab: one was associated with Crohn's disease and the other with rheumatoid arthritis $[17,18]$. Certolizumab is a recombinant antigen-binding fragment (Fab) of humanized monoclonal antibody enhanced with polypropylene glycol (PEG) to prolong the biological half-life of the medication. Its pegylation and lack of Fc fraction makes certolizumab unique in comparison with other anti-TNFa drugs, yet it retains a potential of inducing paradoxical reactions. The risk has been reported to be relatively low and not to increase when the number of patients being treated with certolizumab for Crohn's disease increased [19]; yet these adverse effects remain class-specific. Most cases found in the literature are also of the psoriasiform type: de novo palmoplantar pustulosis followed by pustular psoriasis [20], de novo plaque psoriasis [21] or even one case of psoriatic alopecia that developed 6 months after certolizumab had been introduced into the treatment regimen of a patient with prior diagnosed psoriasis [8]. The 
Table 1 All paradoxical reactions to certolizumab reported to date

\begin{tabular}{|c|c|c|c|c|c|}
\hline $\begin{array}{l}\text { First author of study } \\
\text { (year of publication) }\end{array}$ & Gender & $\begin{array}{l}\text { Age of } \\
\text { patient } \\
\text { (years) }\end{array}$ & Primary condition & $\begin{array}{l}\text { Duration } \\
\text { of therapy }\end{array}$ & Type of reaction \\
\hline Sakai (2017) [22] & Male & 63 & Rheumatoid arthritis & 3 months & $\begin{array}{l}\text { Folliculitis-like lichenoid } \\
\text { sarcoidosis }\end{array}$ \\
\hline Koizumi (2017) [20] & Female & 71 & Rheumatoid arthritis & 10 days & $\begin{array}{l}\text { Palmoplantar pustulosis, } \\
\text { generalized pustular } \\
\text { psoriasis }\end{array}$ \\
\hline $\begin{array}{l}\text { Aragón-Miguel (2019) } \\
\text { [8] }\end{array}$ & Female & 45 & $\begin{array}{l}\text { Sacroilitis, palmoplantar } \\
\text { psoriasis }\end{array}$ & 6 months & Psoriatic alopecia \\
\hline Kobaner (2018) [21] & Female & 46 & Ankylosing spondylitis & 2 months & Psoriasiform \\
\hline $\begin{array}{l}\text { Villalobos-Sánchez } \\
\text { (2019) [23] }\end{array}$ & Male & 57 & Rheumatoid arthritis & 3 months & Palmoplantar pustulosis \\
\hline Mocciaro (2009) [24] & Female & 42 & Crohn's disease & 7 months & $\begin{array}{l}\text { Plaque psoriasis, } \\
\text { palmoplantar pustular } \\
\text { psoriasis }\end{array}$ \\
\hline Klein (2010) [25] & Female & 26 & Crohn's disease & 7 months & $\begin{array}{l}\text { Plaque psoriasis, pustular } \\
\text { psoriasis }\end{array}$ \\
\hline Shelling (2012) [26] & Male & 78 & $\begin{array}{l}\text { Rheumatoid arthritis, } \\
\text { palmoplantar pustular } \\
\text { psoriasis }\end{array}$ & 1,5 month & Pustular psoriasis \\
\hline Fischer (2017) [27] & Male & 38 & Plaque psoriasis & 1 week & $\begin{array}{l}\text { Guttatte psoriasiform } \\
\text { dermatitis }\end{array}$ \\
\hline Protic (2016) [28] & ND & ND & Crohn's disease & ND & Psoriasis \\
\hline \multirow[t]{3}{*}{ Eickstaedt (2017) [29] } & Male & 14 & Crohn's disease & 3 months & Psoriasis \\
\hline & Female & 17 & Crohn's disease & ND & Psoriasis \\
\hline & Female & 18 & Crohn's disease & 6 months & Psoriasis \\
\hline Our case (2020) & Female & 34 & Ankylosing spondylitis & 6 months & $\begin{array}{l}\text { PG, palmoplantar pustular } \\
\text { psoriasis, scalp psoriasis }\end{array}$ \\
\hline
\end{tabular}

$N D$ No data available, $P G$ pyoderma gangrenosum,

histopathology of this latter case showed combined features of alopecia areata and psoriasis, with a subsidence of lesions following the switch to treatment with ustekinumab [8]. One case of a rare folliculitis-like lichenoid sarcoidosis has also been reported in a patient after 3 months of rheumatoid arthritis treatment, with the patient showing a good response after cessation of treatment with certolizumab [22].
To the best of our knowledge, our case report is the first report of a patient with overlapping pyoderma gangrenosum, palmoplantar psoriasis and psoriatic alopecia. All reports of certolizumab-induced paradoxical skin reactions to date, including our case, are given in Table 1 [8, 21-29].

Most cases of paradoxical skin reactions respond well to topical agents, including 
steroids, calcineurin inhibitors and vitamin D analogues. At a body surface area (BSA) of 5 to $10 \%$ they are mild enough not to require discontinuation of the biologic treatment. In moderate to severe cases with more than $10 \%$ of BSA involvement, with pain or pruritus, it is still possible to continue treatment with anti-TNF $\alpha$ with added phototherapy, systemic steroids, MTX, acitretin or cyclosporine. Discontinuation of anti-TNF $\alpha$ therapy is recommended when the cutaneous symptoms are severe and cause a significant impairment of the quality of life, [1]. However, as there is only a $50 \%$ chance of spontaneous improvement, the introduction of a different biologic agent should be seriously considered, preferably one with a different mechanism of action. The most effective biologial agents for treating paradoxical skin reactions are ustekinumab (anti-IL-12/23) and tocilizumab (anti-IL-6R) [1]. In our case, due to a lack of access to these two biologic agents, we withdrew our patient from treatment with the triggering anti-TNFa drug (certolizumab) and then initiated combined treatment with secukinumab and MTX and topical treatment with corticosteroids. The latter treatment regimen resulted in significant clinical improvement.

In conclusions, paradoxical skin reactions have to be considered when new cutaneous lesions appear in a patient with no previous immuno-mediated chronic skin condition or as an exacerbation or changed morphology of an already existing skin disease. We present here a case of a paradoxical skin reaction as an adverse effect to certolizumab, with clinical manifestations of both pyoderma gangrenosum and psoriasis. To the best of our knowledge this is the first reported case of certolizumab-induced pyoderma gangrenosum. Moreover, atypical, complex, overlapping cases are extremely rare and constitute a therapeutic challenge. The pathophysiology of such cases remain hypothetical, but as more indications and new classes of biologic drugs are emerging, clinicians are likely to experience and investigate other similar cases. Further research is needed to be able to predict which patients are prone to these types of reactions.

\section{ACKNOWLEDGEMENTS}

Funding. No funding or sponsorship was received for this study or publication of this article.

Authorship. All named authors meet the International Committee of Medical Journal Editors (ICMJE) criteria for authorship for this article, take responsibility for the integrity of the work as a whole, and have given their approval for this version to be published.

Authorship Contributions. Anna Gawdzik wrote the manuscript. Małgorzata Ponikowska and Jacek C. Szepietowski contributed to the medical care and interpretation of the results. Zdzisław Woźniak was responsible for histological assessment. All authors commented on and approved the manuscript.

Disclosures. Anna Gawdzik, Małgorzata Ponikowska, Alina Jankowska-Konsur, Zdzisław Woźniak and Joanna Maj have nothing to disclose. Jacek C. Szepietowski is a member of the journal's Editorial Board.

Compliance with Ethics Guidelines. This case report was written after receiving oral and written consent from the patient and was compliant with the University Hospital ethical guidelines. Written consent was also obtained from the patient and for the publication of the patient's clinical photographs.

Data Availability. Data sharing is not applicable to this article as no datasets were generated or analyzed during the current study.

Open Access. This article is licensed under a Creative Commons Attribution-NonCommercial 4.0 International License, which permits any non-commercial use, sharing, adaptation, distribution and reproduction in any medium or format, as long as you give appropriate credit to the original author(s) and the source, provide a link to the Creative Commons licence, and indicate if changes were made. The images or other third party material in this article are 
included in the article's Creative Commons licence, unless indicated otherwise in a credit line to the material. If material is not included in the article's Creative Commons licence and your intended use is not permitted by statutory regulation or exceeds the permitted use, you will need to obtain permission directly from the copyright holder. To view a copy of this licence, visit http://creativecommons.org/licenses/by$\mathrm{nc} / 4.0 /$.

\section{REFERENCES}

1. Garcovich S, De Simone C, Genovese G, Berti E, Cugno M, Marzano AV. Paradoxical skin reactions to biologics in patients with rheumatologic disorders. Front Pharmacol. 2019;10:282.

2. Sand FL, Thomsen SF. Off-label use of TNF-alfa inhibitors in a dermatological university department: retrospective evaluation of 118 patients. Dermatol Ther. 2015;28(3):158-65.

3. Hawryluk EB, Linskey KR, Duncan LM, Nazarian RM. Broad range of adverse cutaneous eruptions in patients on TNF-alfa antagonists. J Cutan Pathol. 2012;23:481-2.

4. Havmose M, Thomsen SF. Development of paradoxical inflammatory disorders during treatment of psoriasis with TNF inhibitors: a review of published cases. Int J Dermatol. 2017;56:1087-102.

5. Viguier M, Richerre $\mathrm{P}$, Bachelez $\mathrm{H}$, Wendling D, Aubin F. Paradoxical adverse effects of anti-TNF alfa treatment: onset or exacerbation of cutaneous disorders. Expert Rev Clin Immunol. 2009;5(4): 421-31.

6. Brown G, Wang E, Leon A, et al. Tumor-necrosis factor- $\alpha$ inhibitor induced psoriasis: systematic review of clinical features, histopathological findings, and management experience. J Am Acad Dermatol. 2017;76:334-41.

7. Cabaleiro T, Prieto-Perez R, Navarro R, et al. Paradoxical psoriasiform reactions to anti-TNFalfa drugs are associated with genetic polymorphisms in patients with psoriasis. Pharmacogenom J. 2016;16: 336-40.

8. Aragón-Miguel R, Calleja-Algarra A, Vico-Alonso C, et al. Psoriatic alopecia-like paradoxical reaction to certolizumab pegol. Int J Dermatol. 2019;58: e118-20.
9. Osório F, Magro F, Lisboa C, et al. Anti-TNF- $\alpha$ induced psoriasiform eruptions with severe scalp involvement and alopecia: report of five cases and review of the literature. Dermatology. 2012;225: $163-7$.

10. Martina E, Campanati A, Giuliodori K, Offidani A. Hidradenitis suppurativa in Crohn's disease during adalimumab therapy: a paradox? Acta Dermatovenerol Alp Pannonica Adriat. 2017;26(1):21-3.

11. Ashchyan HJ, Butler CD, Nelson CA, et al. The association of age with clinical presentation and comorbidities of pyoderma gangrenosum. JAMA Dermatol. 2018;154(4):409-14.

12. Ashchyan HJ, Nelson CA, Stephen S, James WD, Micheletti RG, Rosenbach M. Neutrophilic dermatoses. Pyoderma gangrenosum and other boweland arthritis-associated neutrophilic dermatoses. J Am Acad Dermatol. 2018;79(6):1009-22.

13. Vandenunere K, Luyten F, Verschueren P, Lories R, Segaert S, Westhovens R. Pyoderma gangrenosum developing during therapy with TNF- $\alpha$ antagonists in a patient with rheumatoid arthritis. Clin Rheumatol. 2007;26:2205-6.

14. Jaimes-López N, Molina V, Arroyave JE, et al. Development of pyoderma gangrenosum during therapy with infliximab. J Dermatol Case Rep. 2009;3(2):20-3.

15. Kowalzick L, Bertolini J, Baumann C, Walther B, Truhm B, Eickenscheidt L. Paradoxical reaction to etanercept: development of pyoderma gangrenosum during therapy of psoriasis arthritis. J Dtsch Dermatol Ges. 2013;11:447-9.

16. Skalkou A, Manoli SM, Sachinidis A, et al. Pyoderma gangrenosum and pyogenic arthritis presenting as severe sepsis in a rheumatoid arthritis patient treated with golimumab. Rheumatol Int. 2018;38: 161-7.

17. Hurabielle C, Schneider P, Baudry C, Bagot M, Allez M, Viguier M. Certolizumab pegol-a new therapeutic option for refractory disseminated pyoderma gangrenosum associated with Crohn's disease. J Dermatol Treat. 2016;27(1):67-9.

18. Cinotti E, Labeille B, Perrot JL, Pallot-Prades B, Cambazard F. Certolizumab for the treatment of refractory disseminated pyoderma gangrenosum associated with rheumatoid arthritis. Clin Exp Dermatol. 2014;39:750-1.

19. Loftus EV Jr, Colombel JF, Schreiber S, et al. Safety of long-term treatment with certolizumab pegol in patients with Crohn's disease, based on a pooled analysis of data from clinical trials. Clin Gastroenterol Hepatol. 2016;14:1753-62. 
20. Koizumi H, Tokuriki A, Oyama N, et al. Certolizumab pegol, a pegylated anti-TNF- $\alpha$ antagonist, caused de novo-onset palmoplantar pustulosis followed by generalized pustular psoriasis in a patient with rheumatoid arthritis. J Dermatol. 2017;44(6): 723-4.

21. Kobaner GB, Polat Ekinci A, Yilmaz Z, Copur S. Psoriasiform skin eruption in a patient receiving certolizumab pegol for ankylosing spondylitis: report of a case and review of the literature. Dermatol Ther. 2018;31(5):e12693.

22. Sakai H, Nomura W, Sugawara M. Certolizumab pegol- induced folliculitis-like lichenoid sarcoidosis in a patient with rheumatoid arthritis. Case Rep Dermatol. 2017;9(3):158-63.

23. Villalobos-Sánchez L, Larena-Grijalba C, Alía-Jiménez A, Sifuentes-Giraldo WA. Certolizumab pegolinduced palmoplantar pustulosis: a case report and review of the literature. Reumatol Clin. 2019;15(6): e163-5.

24. Mocciaro F, Renna S, Orlando A, Cottone M. Severe cutaneous psoriasis after certolizumab pegol treatment: report of a case. Am J Gastroenterol. 2009;104(11):2867-8.
25. Klein RQ, Spivack J, Choate KA. Psoriatic skin lesions induced by certolizumab pegol. Arch Dermatol. 2010;146(9):1055-6.

26. Shelling ML, Vitiello M, Lanuti EL, Miteva M, Romanelli P, Kerdel FA. A case of palmoplantar pustulosis induced by certolizumab pegol: new anti-TNF- $\alpha$ demonstrates the same class effect. J Clin Aesthet Dermatol. 2012;5(8):40-1.

27. Fischer R, DaCunha M, Rajpara A. Certolizumabinduced guttate psoriasiform dermatitis. Dermatol Online J. 2017;23(1).

28. Protic M, Schoepfer A, Yawalkar N, Vavricka S, Seibold F. Development of psoriasis in IBD patients under TNF-antagonist therapy is associated neither with anti-TNF-antagonist antibodies nor trough levels. Scand J Gastroenterol. 2016;51(12):1482-8.

29. Eickstaedt JB, Killpack L, Tung J, Davis D, Hand JL, Tollefson MM. Psoriasis and psoriasiform eruptions in pediatric patients with inflammatory bowel disease treated with anti-tumor necrosis factor alpha agents. Pediatr Dermatol. 2017;34:253-60. 